CASE NOTES

\title{
OCULAR PATHOLOGY IN A CASE OF XANTHOMATOUS BILIARY CIRRHOSIS WITH INTRA-OCULAR INVOLVEMENT *
}

\author{
BY \\ NANCY LEWIS \\ Melbourne, Australia
}

IN a previous communication (Lewis, 1950) the ocular findings in a case of xanthomatous biliary cirrhosis were described. The continued progress of the general disease resulted in the patient's death in May, 1951, in a country hospital in Victoria. The history leading up to the terminal stages of the condition is reported in the present paper, together with postmortem and histological findings.

\section{Case Report}

History.-The last ocular examination was made in January, 1951. At that time the patient had gained weight and the xanthomata had cleared from the creases of the hands; xanthelasmata of the eyelids were present, and the conjunctivae showed an icteric tinge.

In the right eye vision was limited to perception of light only; in the left it was 6/9 with correction. The appearance of the right fundus was as previously described (Lewis, 1950). The left fundus appeared normal.

During the following 4 months the patient remained well, but on the day preceding her death she complained of a pain in the ankle. This was followed the next day by a sudden attack of acute pulmonary oedema, which failed to respond to the usual treatment. Death occurred one hour after admission to hospital.

Clinically, the patient was jaundiced with a super-imposed cyanotic tinge. Xanthelasmata were present on the eyelids. She had small bleeding sores scattered over the limbs, and some irregular bruised areas on the limbs and face. She was bleeding from the gums and had clotted blood in her nostrils. On auscultation of the chest, loud coarse râles obscured all other sounds. The liver was enlarged to the umbilicus.

Post-Mortem Examination.-The amount of haemorrhage was surprising. There were diffuse patches in the lungs, bowel, and kidneys, and haemorrhages in the lymph glands. The liver revealed advanced biliary cirrhosis. The intra- and extra-hepatic biliary tracts were quite normal and no internal or external obstruction could be demonstrated.

Histological sections of the abdominal organs were poor, owing to the impossibility of early fixation of the material.

Pathological Report on the Eyes.-Frozen sections of both eyes were made before re-embedding in celloidin.

Sections of the right eye were made in the horizontal meridian. A large mass of connective tissue separated the retina from the choroid. In places Bruch's membrane had broken down, and the mass of granulation tissue, which contained fibroblasts varying

* Received for publication March 4, 1952. 


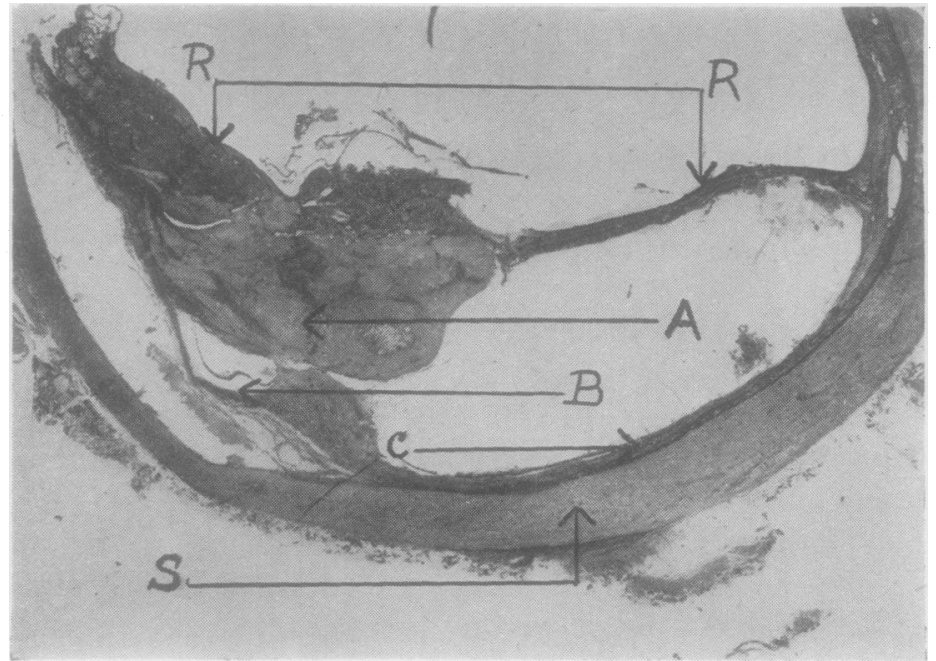

FIG. 1.-Horizontal section of right eye, showing large mass of connective tissue A, separating retina $\mathbf{R}$ from choroid $\mathbf{C}$ and sclera $\mathbf{S}$. At $B$ is seen the breaking down of Bruch's membrane and the attachment of the granulation tissue to the choroid.

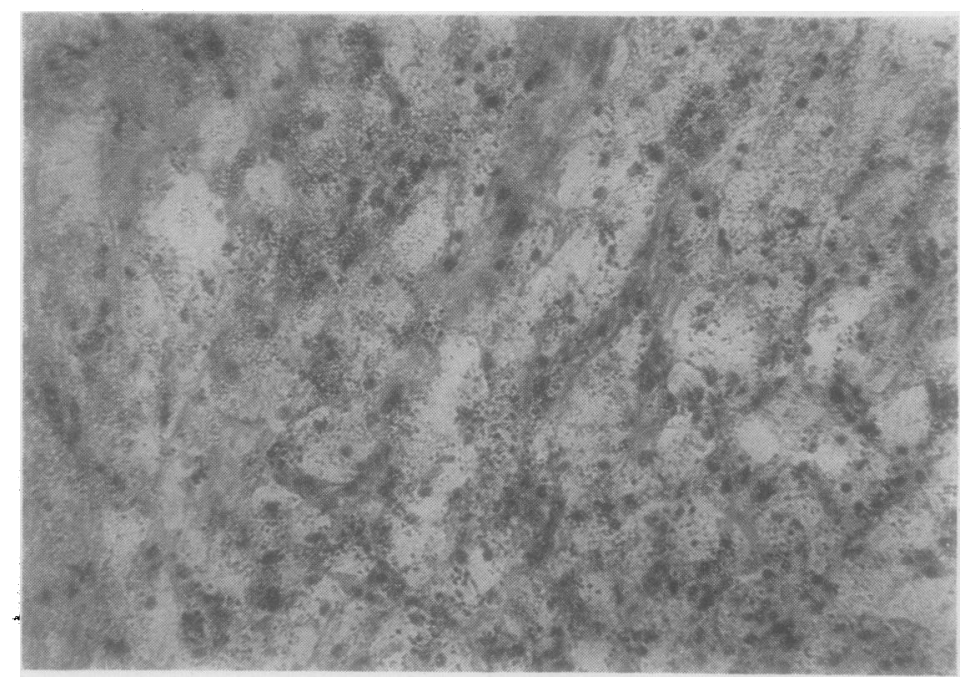

Fig. 2.-Medium-power view of the mass of tissue A showing typical xanthoma cells, granulation tissue, and scattered granules of retinal pigment. 
from young to the more attenuated spindle cells, was directly attached to the choroid. There was round-cell infiltration of the choroid in these areas, and the pigment from the pigment epithelium was scattered through the granulation tissue. On the inner aspect it had infiltrated the retina in the vicinity of the vessels. Xanthoma cells were present in the retina and the choroid as well as at the periphery of the granulation tissue. The centre of the mass was occupied by cholesterin crystals. Frozen sections stained with Sudan III gave the characteristic reaction in the retina, choroid, and granulation tissue. The sections showed all the changes of primary essential xanthomatosis (Thannhauser, 1940).

Frozen sections of the left eye showed small areas of fatty degeneration in the choroid.

I am indebted to Dr. Kevin O'Day of Melbourne for the pathological report on the eyes.

\section{REFERENCES}

LEWIS, N. (1950). British Journal of Ophthalmology, 34, 506.

Thannhauser, S. J. (1940). "Lipoidoses: Diseases of the Cellular Lipid Metabolism ", p. 88. Oxford University Press, New York. 